The authors identify and discuss the many complexities involved in the translation of scientific information in the social sciences into forms usable for solving problems of practice in education. As a means of appropriately handling these complexities and the issues that arise, they prescribe a series of stages to be followed from the advent of a practitioner's situational problem to the design of a response to it. They assert that unless the process of translation is conducted with the prescribed level of understanding, appreciation, and rigor, the application of knowledge will be inaccurate.

\title{
Solving Problems of Practice in Education
}

A Prescriptive Model for the Use of Scientific Information

\section{ROBERT D. BOYD}

University of Wisconsin-Madison

ALLEN MENLO

University of Michigan

This article is the outgrowth of a project that began initially as our shared concern, which is illustrated in the following two examples: Two adult educators were discussing how they worked with anxious students in their classes. Both were familiar with and made use of a particular set of studies on anxiety, but each had developed different solutions that revealed fundamental conflicts in their application of the basic information. The conflict was not due to reading the primary source incorrectly but to making assumptions about the findings that would be in harmony with their own approach to teaching. The second example involves two adult educators arguing about the role of anxiety in learning. One educator was rejecting any benefits the presence of anxiety could have on learning while the other educator was proposing the opposite position-that anxiety could be of benefit in learning. It was apparent

Authors' Note: The authors are listed alphabetically. Each author contributed equally to the article.

Knowledge: Creation, Diffusion, Utilization, Vol. 6 No. 1, September 1984 59-74 c 1984 Sage Publications, Inc. 
that each educator's position was based on different sets of findings and that they had paid little attention to the contexts of the studies from which the findings arose, the measures of anxiety employed, and the nature of other factors in each of the studies.

These problems may be too hastily dismissed as examples of careless reading, lack of knowledge, or poor listening due to one of a number of reasons from status needs to an adversary relationship. In some incidents these explanations may be correct; however, in other cases the problem involves the failure to make appropriate and accurate translations of information.

It is important at this point to clarify the critical characteristics of the terms "information" and "translation." In this article we speak of two types of information: scientific and practical. We view scientific information as findings derived from research studies, and practical information as the product of experience and practice. (The meanings of these two terms will be more fully developed in various parts of this article.) "Translation" means changing from one place, position, or condition to another without change in quality or quantity. The synonym for this would be "conversion." Thus our use of "translation" refers to the conversion of research findings into forms suitable for their use in solving a problem of a practical nature, without losing the initially intended meaning of the scientific information in the conversion process.

The translation of information in education is not restricted to the instruction of learners. Adult educators are continually making applications of findings and theories from such fields as psychology, sociology, business and political science to problems encountered in administration and the planning and organization of programs. The translation is often direct and there is little or no discussion of the assumptions and unique conditions that determine the extent of tie between the source of the information and the application of the information. For example, findings that indicated the successfulness of nondirective leadership in facilitating the movement of laboratory learning groups through developmental phases were employed in choosing leadership behaviors for facilitating substantive learning in an adult classroom group. Such translation may be appropriate, but the appropriateness cannot be determined until there is a careful examination of what is common and not common between the two settings, including aims, conditions, clientele, and goals.

The problem of translating scientific information into practice terms is not endemic only to education. The problem exists in industry, 
agriculture, social services, health, indeed in practically every area of human endeavor. To meet the idiosyncracies that have arisen in each area, the translation of information occurs in several different types of formulations. The most pervasive type of formulation is the "R\&D paradigm." This paradigm was developed by industry where it has been reworked and improved upon and now describes a systematic flow of information from basic research through stages of applied research, design development, production, and distribution (Hall, 1962). The R\&D paradigm has found its way into social science, particularly social work (Rothman, 1974, 1980) and education (Eidell and Kitchel, 1968). Rothman (1974) surveyed the literature with the goal of proposing a set of action principles that he labeled "application principles." Rothman may be characterized as a knowledge broker in that he acted as an intermediary between the producer of information and the candidate who could make use of the information. In his initial volume he set out the information translation paradigm that he had employed in moving information from research studies to possible operational or implementation programs, but it was in his second work (1980) that Rothman wrote specifically about the function of the paradigm. It is clear from this presentation of the model that it was not viewed from the perspective of the problem solver but instead from the perspective of the knowledge organizer. Guba (1968) and Havelock (1968) both argued for a form of an R\&D model in education. Havelock also set out a system of stages similar to but not as elaborate as Rothman's paradigm.

The $R \& D$ model is different in a fundamental way from the model we are proposing here. It proposes a series of stages from basic research to diffusion and implementation in specific situations where the information could solve existing problems or improve performance. The model does not begin with the problem in a given situation as is the case with the model we are proposing here. The R\&D model may be thought of as a movement of information to problem. The model we propose is the reverse of this: It is the movement of problem to information.

There are a number of other models, for example Rogers's (1962) Diffusion and Innovation Model, Lindquist's (1978) Strategies for Change, and Brickell's (1966) Dynamics of Change. The most extensive review of this literature was conducted by Havelock (1969). After reviewing over 4000 items he proposed that there were four basic models-namely, (1) research, development, and diffusion perspective; (2) social interaction perspective; (3) problem-solver perspective; and (4) linkage perspective. As the first two perspectives do not begin with the individual confronting a problem in practice they are not directly rele- 
vant to our focus. The latter two perspectively involve the individual facing a problem in practice and the need to translate scientific information into action for the solution of the problem.

The linkage perspective involves the transaction between the user system and resource system. From practically every standpoint this is the most desirable model. It brings the individual with a given problem in direct communication with the individuals who have the resources to provide the necessary information that can be translated into actions that are unique and appropriate to the given problem. There are occasions when this arrangement can not be made, and it is when faced with this limitation that we must fall back upon the problem-solver perspective or model.

Havelock (1969) in his review of the problem-solver model delineated its features and then presented criticisms of the model. It is clear from his review that the problem-solver model is viewed as being directed by the need to answer a particular problem. That is, the translation of information is directed by a problem stated in the form of an informationseeking question. We propose that there are three levels of questions: specifically, tactic-seeking questions, strategy-seeking questions, and knowledge-seeking questions. There is a second quality that distinguishes our model from those that Havelock reviewed and this concerns the criteria that are employed to determine the acceptability of information. The scientific quality of the information was discussed in Havelock's review, but ontological and valuation issues were not addressed. We see the consideration of these issues as being critical to the use of the problem-solver perspective. The role of ontological and valuational considerations will be treated later in this article as will the three types of problem questions involved in the translation of information. Our purpose here is to establish the unique contributions our work makes to the existing literature.

From the development of the statement of the problem by the practitioner to the identification of appropriate scientific information and the translation of this information back to the problem requires a good deal of careful and thoughtful work. The practitioner who wishes to use scientific information appropriately must follow a systematic series of steps in developing solutions to practice problems. This process and the issues inherently within it comprise one realm-the instrumental realm - of our model for knowledge utilization in problem-solving. This article discusses just the instrumental realm, although the entire model is composed of three realms. A second realm of the model, the psychoso- 


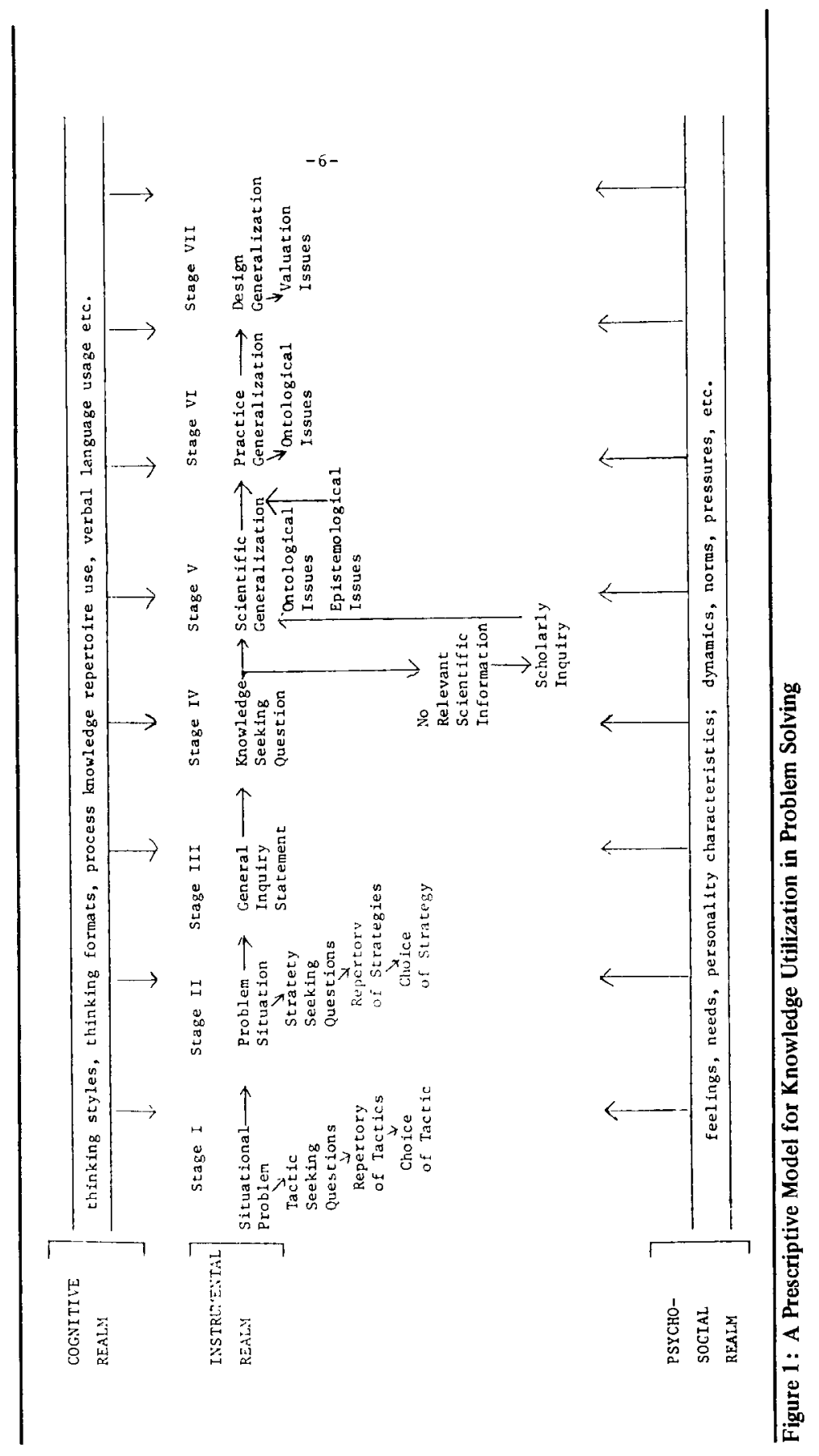


cial realm, is comprised of the affective factors that may come to bear at any point on the practitioner's movement through the steps of problemsolving. These factors may be feelings, values, needs, predispositions, and other intrapersonal factors, as well as interpersonal, group, organizational, and community dynamics, norms, and pressures that are experienced at various levels of consciousness by the practitioner. As forces, they influence the quantity, quality, and rate of practitioner actions in problem-solving. A third realm of the model, the cognitive realm, contains intellectual factors that may impinge singly, recurrently, or ongoingly on the movement of the practitioner through the steps of problemsolving. These factors may exist as thinking styles, thinking formats, theoretical perspectives, process knowledge repertoire, verbal language usage, and other cognitive processes that the practitioner brings to his or her problem-solving efforts and, as forces, also influence the quantity, quality, and rate of the practitioner's problem-solving actions.

What follows now is a schematization (Figure 1) of the model. The diagram delineates the various aspects and stages of the instrumental realm while the discussion that follows describes and clarifies it by guiding the reader through a possible venture of a practitioner in search of a solution to a practical problem. Following this explanation, the psychosocial and cognitive realms will be discussed in more general terms.

Our practitioner is a male instructor of an adult evening class on social issues. Since the enrollment is small, the class is being conducted as a seminar. A few sessions had passed, two members were not saying anything during the sessions, and the instructor's efforts at getting them to participate verbally had been unsuccessful. The instructor viewed this situation as a problem: I have two members in my seminar who hardly ever say or do anything and I have been unable to get them to participate. This is clearly a situational problem. The instructor saw the problem in terms of an immediate situation facing him and stated the problem in those terms. It is with this meaning that the label "situational problem" is being used.

Practitioners who seek help for difficulties stated as situational problems usually ask tactic-seeking questions. The tactic-seeking question that the instructor asked was, What can I do to help these two members become more active contributors in the seminar? Questions of this kind are understood to be in search of specific ways (e.g., techniques) to handle the difficulty in its immediate form. These ways to handle the difficulty are called tactical because the action to be carried out has only a limited or immediate end in view. The instructor wanted to know how 
to help these two members; and if we accept the question in its literal terms, he was not seeking a more fundamental level of knowledge. Indeed, he may be satisfied to have an answer drawn from some repertory of tactics. For instance, someone may suggest that he ask all seminar members to prepare a brief statement on a central issue and present their statements at the next seminar session.

Referring to Figure 1, we have just isolated Stage I and described a practitioner's movement through the components of that stage-if it were the practitioner's desire to settle for a tactic rather than scientific information. If, however, the instructor can be persuaded to look to scientific information instead of taking action based on practice, then the instructor can be assisted to move his problem to another level of discourse-the problem situation level.

At the problem situation level, there is a statement of a general difficulty that practitioners have encountered in similar settings. A broader perspective of the problem is thus achieved. The elements involved are identified in plural, nonspecific, categorical form and their interrelationships are clarified. Our instructor then restated his situational problem as a problem situation: There are leaders of small learning groups who are unable to get reluctant members to participate.

Practitioners who seek help for difficulties stated as problem situations usually ask strategy-seeking questions to discover methods, procedures, or approaches in order to handle particular difficulties. If our instructor were ready to settle for a strategy rather than seek further for scientific information, his question might be, What can leaders of small learning groups do to get members who are reluctant to participate to participate more? While both tactic-seeking questions and strategy-seeking questions are principally pragmatic inquiries expressing expedient motives, the strategy-seeking question is at a slightly higher level of abstraction. It makes an appeal for solutions to a general situation rather than a specific situation problem. Someone may advise our instructor to design his class sessions in a way that employs ad hoc and permanent subgroups so that members may find it easier to speak to each other.

Again referring to Figure 1, we have just described a practitioner's movement through the components of Stage II-if it were the practitioner's desire to settle for a strategy rather than scientific information. It may be inaccurate to describe concerns for tactics or strategies as narrowly utilitarian, but their intent is not primarily to further one's scientific or formal knowledge as a basis for deriving or selecting solutions to difficulties. 
If we can interest our instructor in turning to scientific information for solutions to his problem, in expanding his knowledge repertoire from which he can then develop other solutions in the future, and in learning a format for the translation of that knowledge into practice terms, then we would ask him to re-express the problem situation as a general inquiry statement. A general inquiry statement points out the possible existence of relationships among variables germane to both the problem situation and the initial situational problem. In this case, our instructor's general inquiry statement might be this: There are factors that influence the participation of members in a learning group.

The general inquiry statement should be followed by a knowledgeseeking question. The intent of a knowledge-seeking question is to establish what scientific information exists that could be used to resolve a specified problem and not what information on procedures could be incorporated into a plan of action. Questions of this kind contain no specific reference to a particular situation or person, but probe for the existence of influence or associative relationships between variables. Also, questions of this kind are usually in search of generalizations that eventually advise what actions might be wisest to take in order to influence the phenomenon under consideration. Our instructor's knowledgeseeking question might be, What factors influence the participation of members in a learning group?

The postponement of seeking more immediate solutions to a problem and raising knowledge-seeking questions moves the seeker's attention from a concern with practical information to a concern with scientific information. The tactic and strategy forms of information are usually transferred directly from a particular source to a given situation. Such transfers of information do not involve an examination of the conceptual framework upon which the tactics and strategies are based. The tactics and strategies are employed as the user believes they can be used to resolve the difficulties being encountered. Sources of such information are usually exchanges among professionals of ideas derived from practice. As long as one settles for tactic-seeking or strategy-seeking questions, scientific information as a source of problem solving is likely to be more ignored than used. Referring to Figure 1, we have just explained the nature of Stages III and IV.

Following a knowledge-seeking question, there exist two possibilities. One is where there is scientific information available, the other is where no scientific information exists. Figure 1 shows the two alternatives as a bifurcated arrow, one arrow leading to scientific generalization, the other leading to no relevant scientific information. Each of these will be discussed in turn. 
Ideally, a knowledge-seeking question retrieves scientific generalizations-statements based on empirical research that meet the standards of scientific explanation. Two scientific generalizations in response to our instructor's knowledge-seeking question could be the following: Members who have a basic sense of security in the group are more likely to take risks within the group than members who do not; and, members who perceive themselves as having high power and perceive other members as being supportive toward them are likely to feel more secure within the group than members who perceive themselves as having low power and perceive other members as being nonsupportive. These scientific generalizations, as is the case with all scientific generalizations, are based within a conceptual framework that not only delineates the specifications for the key terms of the statement, but also defines the assumptions and propositions within which the statement is bounded.

It is also possible for a knowledge-seeking question to reap no relevant scientific information. In this case, the question may very well become one that seeks the design of research studies more so than the design of practitioner actions. Thus, finding no relevant information in the proposed model for knowledge utilization is a significant finding since it helps in the "grass roots" identification of areas of needed knowledge development through inquiry and can act as a force toward the expansion of priority information in one's professional field.

If our instructor had retrived the scientific generalizations mentioned above, then he would be in a position to translate them into a practice generalization: A practice generalization is a statement that reorganizes a specificigeneralization into a suggestion for persons as practitioners on what they can do to bring about some outcome desired by the practitioner. It suggests means toward ends. It differs from a tactic or a strategy in that it does not provide specific plans of action, although it clearly identifies a line of action. Tactics and strategies may be based only on the merits of successful practices, but practice generalizations are always based on scientific generalizations. A practice generalization that might be logically developed from the aforementioned scientific generalizations would be this: Leaders of small groups who wish to facilitate members' risk-taking within the group can do so by helping members feel a basic sense of security within the group; and leaders can help members feel a basic sense of security within the group by saying and doing those things that increase members' perceptions of their own power and of the supportiveness of other members and decrease perceptions of nonsupportiveness of other members. This is Stage VI in Figure 1. 
After our instructor has the above-mentioned practice generalization in hand, he would be encouraged to translate it into a design generalization. A design generalization is a logical extension of the practice generalization that adds further suggestions for action. It operationalizes the practice generalization through the use of past experiences, methods literature, and imaginative creations that logically match the generally suggested action in the practice generalization. The design generalization provides suggestions for possible action from which our instructor can select and then concretize each selection through specific methods and techniques responsive to the idiosyncrasies of his particular setting. Our instructor might develop the following design generalization: In order to increase the extent to which members will perceive other members as being supportive, the leader could arrange the tables and chairs in a circle, provide name tags with smiling faces, and ask members to speak initially about their positive expectations for the group. In order to increase members' perceptions of their own power, the leader could listen to and reflect back members' contributions, ask members to help develop the group's agenda, and help the group's work.

In some situations one design generalization may be an operationalization of two or more complementary and compatible practice generalizations. The conditions of complementarity and compatibility should be especially noted. In combining practice generalizations, it is critical to establish that the scientific generalizations that serve as the source of the practice generalizations are compatible. For example, if one practice generalization has been developed from research findings on college students and a second from research findings on middle management executives, the compatibility is suspect; and even more so when the setting in which the design generalization is to be applied is a small group of neighbors facing a community problem.

Referring to Figure 1, our discussion of scientific, practice, and design generalizations has explained Stages V, VI, and VII. Our instructor would now confront his initial situational problem again and apply to it the specific procedures, methods, and techniques that he has developed as a means of concretizing his design generalization.

It should be noted in Figure 1 that the terms ontological, epistemological, and valuational have been indicated at certain stages. These terms first appear in the sequence where a scientific generalization is found in response to a practitioner's knowledge-seeking question. At this point, issues of an epistemological and ontological nature arise. The practitioner ought to make an inquiry regarding the extent to which the study from which the generalization was extracted meets an acceptable 
set of criteria for being scientific. In this regard, there are critical attendant issues of a scientist-practitioner interface nature that demand attention. For instance, the extent to which responsibility for the validity, reliability, and specific application of research-generated generalizations rest with the producers (scientists) and/or the users (practitioners) or with third-party brokers of generalizations (such as textbook writers) must be determined. On occasions, such issues are not addressed and unfortunate and unexplainable outcomes result. Other issues, for instance, the form and ethics of reporting and the responsibilities for the appropriate diffusion of scientific generalizations, have often remained insufficiently explored. We suggest, however, that there are other issues of an epistemological and/or ontological nature that are of equal, if not greater, importance.

In addition to the issue of acceptable criteria mentioned above, another epistemological issue arises when a scientific generalization is proposed by convergence of similiar findings from two or more studies. This issue highlights two areas where serious problems in attempting convergence among the studies may exist. These two problems are operationalized by the following two questions. (1) Are the conceptual frameworks employed by the different studies compatible? For example, one study assumes the existence of the unconscious as a significant variable while another study does not accommodate for the existence of the unconscious. (2) Are the methodological approaches employed by the different studies compatible? Such differences can be observed in studies employing ethnographic methods over against studies making use of the "hypothetico-deductive" approach.

Another epistemological issue concerns the relationship between the means of scholarly inquiry employed to establish a scientific generalization and the type and state of the practice to which the generalization will be applied. This issue is operationalized by the question, Within what conditions was the study conducted and are those conditions sufficiently congruent to the specific field of practice that would permit the scientific generalization to be accepted as being applicable to the given field of practice? For example, it would seem that a program planner whose problems are likely to be macroscopic or field-type in nature ought to be skeptical about using scientific generalizations acquired within a research paradigm calling for a tightly controlled laboratory study. Also, a vocational teacher who is having a problem helping students learn a precise skill should question the employment of a scientific generalization emerging from a research scheme calling for an exploratory, developmental study. 
There are also ontological issues involved in the application of scientific generalizations to problems encountered in fields of practice. Earlier reference was made to the congruence of conceptual frameworks and the problems that may be present when the conceptual frameworks do not share basic assumptions. There are not only epistemological implications involved in such conflicts but there are also ontological implications. For instance, an adult education program director in a correctional institution where an undergirding assumption is that a person's behavior is shaped mainly by environmental forces should question the direct use of a scientific generalization derived from a study that views behavior as being shaped by innate drive for power. The ontological issue is operationalized here by the question, What were the assumptions about human nature which the study adopted and upon which the scientific generalization was structured, and how harmonious or conflicting are those assumptions with the assumptions that undergird the approach the practitioner takes in his or her work? We make the assertion here that the practitioner must examine both the assumptions upon which he or she is basing decisions and those upon which the researcher conducted the study. On the one hand, this may pose expectations that appear to be unreasonable for many practitioners. On the other hand, accuracy of efforts to translate scientific information into practice forms may depend on the presence and use of such expertise. Clearly, there seems to be a dilemma regarding this issue. Perhaps the responsibility for translating accuracy can somehow be shared between the producer of scientific information, the users, and the third-party brokers. This apparently is, as yet, an unanswered question, and one beyond the scope of this article.

Closely allied to the epistemological and ontological issues are issues of valuation. Decisions are made not only on scientific information and assumptions of human nuture but also on what we value and prize. When such a focus is taken, the issue becomes one of valuation. The issue of valuation-that is, what the practitioner prizes or values-seems likely to arise at that step in the sequence where a design generalization is developed from a practice generalization. It is even likely that the issue of valuation may arise early in the sequence and be joined with the ontological and epistemological issues. Indeed it is sometimes difficult to separate out what is valued from what is taken as a valid 
assumption about human nature and sound scientific exploration. The issue of valuation is operationalized, regardless of where it arises, by this question: What values are being expressed explicitly or implicitly by the choices that are being made? For example, two practitioners accept the ontological assumption that adults must be active participants in a learning situation, but one differs from the other on the sharing of control in the conduct of the class. One values a relationship of shared control. The other practitioner values a teacher-directed classroom. Each may argue his or her position on ontological grounds, but the presence of two conflicting valuation systems will be clearly evident in the statements of their positions. By highlighting the existence of the issue of valuation, the model attempts to help practitioners to a greater awareness of those forces that operate in the choice and implementations of selected practices.

\section{Psychosocial Realm}

As stated earlier and as illustrated in Figure 1, the psychosocial realm is composed of the personal or psychic forces and the interpersonal or social variables and forces. In the most inclusive perspective, we also have in mind the Zietgeist. For example, an instructor, although he or she may be knowledgeable about the educational benefits of involving learners in the planning and execution of instructional programs, is unable to let go of the control he or she has as the instructor of the class. This is a personal issue for the instructor; and although such behavior directly affects the implementation of the translation model presented here, the behavior is part of the psychosocial realm and not part of the instrumental realm. The social aspect of the psychosocial realm can be illustrated by the situation in which an instructional group has developed a group culture of mistrust. In such a culture the instructor will experience great difficulty in helping the members to assume responsibilities for the conduct of the group. These limited illustrations of the psychosocial realm show both its significance to and its interrelations with the instrumental realm. It is obvious that a fuller understanding $c^{r}$ the relationship between these two realms would prove helpful, but ${ }^{*}$ would take us beyond the scope of this article. 


\section{Cognitive Realm}

Inspection of Figure 1 shows the existence of another realm that for our purposes has been labeled the cognitive realm. The cognitive realm identifies the intellectual or mental (as opposed to emotional) forces that are employed in thinking about or reflecting upon the conscious aspects of our lives. As an example, some practitioners whose professional lives have been embedded in daily demands of interagency rivalry or community politics may develop a pragmatic, "whatever works" style of thinking about problems. Such a well-practiced approach of seeking the best available maneuver for the given occasion can make it difficult for the practitioner to think at the abstract level, or even honor abstractions as a legitimate style of thinking for the "real world."

Behavioral sciences have added extensively to our knowledge on cognition. To mention only a few studies demonstrates the richness of our current knowledge. For example, investigators have shown not only the existence of but also the role that such factors as cognitive controls (Witkin, 1977; Klein, 1970), stages of intellectual development (Schaie, 1981; Piaget, 1972), styles of thinking (Kolb, 1981; Klausmeier et al., 1974) and strategies of learning (Boyd and Diekelmann, 1981) play in learning and problem-solving. Obviously these various aspects of cognition must affect behaviors in the instrumental realm. An instructor, for example, may have a predisposition for focusing on small units of classroom phenomena and, as a consequence, identify specific points of a situation. Having failed to scan the entire situation the instructor may have missed other points that also should have been taken into account. Movement through the instrumental realm is directly affected by what is brought into it from the cognitive realm by both instructor and learners. As was the case with the psychosocial realm, our purpose here is to simply identify the significance of the cognitive realm to the instrumental realm and to limit the scope of this article to the latter realm.

\section{Summary}

One persistent and critical demand facing practitioners is the translation of scientific information into solutions for practice problems they 
encounter. A review of existing types of information translation models was presented. It was pointed out that most practitioners are restricted to the problem-solver model. We proposed a model that we consider more inclusive and adequate than existing models. The instrumental realm of that model was developed in detail employing not only a description of each stage of the translation process but examples to illustrate how a practitioner would function within each stage. In addition to the contribution made by identifying the sequence of operational stages, the model identified the role that epistemological, ontological, and valuation issues play in the translation of information. The psychosocial and cognitive realms were briefly explained within the limits of this article.

\section{References}

BOYD, R. D. and N. DIEKELMANN (1981) "Problem solving with students," in H. Kanophe and N. Diekkelmann (eds.) Approaches to Teaching Primary Health Care. St. Louis: Moslev.

BRICKELL, H. M. (1966) "The local school system and change," in R. Miller (ed.) Perspectives on Educational Change. New York: Appleton-Century-Crofts.

EIDELL, T. L. and J. M. KITCHEL [eds.](1968) Knowledge Production and Utilization in Educational Administration. Produced in cooperation by the University Council for Educational Administration (Columbus, $\mathrm{OH}$ ) and the Center for Advanced Study of Educational Administration (University of Oregon).

GUBA, E. G. (1968) "Development, diffusion and evaluation," in T. L. Eidell and J. M. Kitchel (eds.) Knowledge Production and Utilization in Educational Administration. Produced in cooperation by the University Council for Educational Administration (Columbus, $\mathrm{OH}$ ) and the Center for Advanced Study of Education Administration (University of Oregon).

HALL, A. D. (1962) A Methodology for Systematic Engineering. New York: Van Nostrand.

HAVELOCK, T. G. (1968) "Dissemination and translation roles," in T. L. Eidell and J. M. Kitchel (eds.) Knowledge Production and Utilization in Educational Administration. Produced in cooperation by the University Council for Educational Administration (Columbus, $\mathrm{OH}$ ) and the Center for Advanced Study of Educational Administration (University of Oregon).

___et al. (1969) Planning for Innovation Through Dissemination and Utilization of Knowledge. Ann Arbor, MI: Center for Research on Utilization of Scientific Knowledge, Institute for Social Research, University of Michigan. 
KLAUSMEIER, H., E. S. SHATALA, and D. A. FRA YER (1974) Conceptual Learning and Development: A Cognitive View. New York: Academic Press.

KLEIN, C. S. (1970) Perception, Motives and Personality. New York: Knopf.

KOLL, G. S. (1981) "Learning styles and disciplinary differences," in A. W. Chickering et al. (eds.) The Modern American College. San Francisco: Jossey-Bass.

LINDQUIST, J. (1978) Strategies for Change. Washington, DC: Council for the Advancement of Small Colleges.

PIAGET, J. (1972) "Intellectual evolution from adolescence to adulthood." Human Development 15: 1-12.

ROTHMAN, J. (1974) Planning and Organizing for Social Change: Action Principles from Social Science Research. New York: Columbia Univ. Press.

(1980) Social R\&D Research and Development in the Human Services. Englewood Cliffs, NJ: Prentice-Hall.

WITKIN, H. A. (1977) "Field dependent and field independent cognitive styles and their educational implications." Rev. of Educ. Research 47, 1: 1-64.

ROBERT D. BOYD is a Professor at the University of Wisconsin-Madison. He received his Ph.D. in educational psychology at the University of Chicago. He was on the faculties of Miami University and Antioch College before coming to the University of Wisconsin. Professor Boyd is Director of the Laboratory for the Study of Small Groups in Adult Education, past editor of Adult Education and has served as Associate Editor of the Journal of Educational Research. He has been Chairman of the Commission of Professors of Adult Education for North America and Chairman of the Research Commission for the Adult Education Research Conference. He is author of several articles reporting his research on adult psychosocial development and on small groups. His publications in the field of adult education include books, monographs, and articles.

ALLEN MENLO is Professor in Educational Foundations, Policy, and Administration and is Faculty Associate in the Center for Research on Learning and Teaching and Director of the Frankfurt-Michigan-Sheffield Cross-Cultural Study Program at the University of Michigan. He is also a member of the Executive Council of the Society for Cross-Cultural Research and Editor of the Society's Newsletter. His major research interests are the antecedents of participation and the cross-cultural study of teaching and schooling. Recent publications are "Antecedents to Member Participation Within Small Groups: A Review of Theory and Research," and "Training Leaders to Facilitate Participation in Adult Groups"-both in the Journal of Specialists in Group Work. His Master's degree was in clinical psychology and his doctorate in educational psychology. 